\title{
The Effect of Behavior on Short-Term Memory Capabilities
}

\author{
Unun Umaran ${ }^{1,2 *}$ \\ ${ }^{1}$ Faculty of Sport and Health Education, ${ }^{2}$ Physical \\ Education, Health and Recreation \\ ${ }^{1}$ Universitas Pendidikan Indonesia, ${ }^{2}$ Universitas Islam 45 \\ Bekasi \\ ${ }^{1}$ Bandung, Indonesia, ${ }^{2}$ Bekasi, Indonesia \\ *ununumaran@upi.edu
}

\author{
A Suhermana, H Subarjah \\ Faculty of Sport and Health Education \\ Universitas Pendidikan Indonesia \\ Bandung, Indonesia
}

\author{
M Zaky ${ }^{1,2}$ \\ ${ }^{1}$ Faculty of Sport and Health Education, ${ }^{2}$ Post Graduate \\ ${ }^{1}$ Universitas Pendidikan Indonesia, ${ }^{2}$ Universitas Muhammadiyah Prof. DR, Hamka \\ ${ }^{1}$ Bandung, Indonesia ${ }^{2} \mathrm{Jakarta}$, Indonesia
}

\begin{abstract}
The study was conducted because several theories say physical activity can provide a positive influence on cognitive function. The research method uses Ex Post Facto with an intactgroup comparison approach. The research sample is a member of the bike to work community, which is between 20 and 35 years old with 30 people. The sampling technique uses purposive sampling. The instrument used is a Letter Test or Number Test. Independent samples t-test to see the effect of cycling activity on the ability of short term memory by looking at the difference in average scores sample group. The results showed that the average score of the cycling group's ability was better than the motorized group (control). In other words, cycling activity has a positive influence on the ability of short term memory.
\end{abstract}

Keywords-cycing activity; short term memory; the effect of behavior

\section{INTRODUCTION}

To get a healthy body, of course, it must be done with physical activity or regular exercise. This applies to various ages, be it children, adolescents, adults, and the elderly. Phenomena that occur at this time, especially for adults who are preoccupied with work routines experience a lack of physical activity caused by routine work. Thus of course it will result in physical fatigue and does not rule out the possibility of memory or memory will also quickly experience fatigue. There are several assumptions that if not balanced with physical activity cognitive abilities will decrease. This is in accordance with the opinion of Manoux [1], in his study of the relationship between physical activity and cognitive function in middle age namely all public servants aged 35-55 years based in London department, suggested that lack of physical activity was a risk factor for decreased cognitive function, our results showed a small but significant the relationship between physical activity and cognitive function in middle age. Age and gender adjusted to the relationship between physical activity and cognitive performance is greatly weakened by other than education and socio-economic. The aspect of cognitive function that mostly decreases with age is fluid intelligence, and our results show that low levels of physical exercise have become a risk factor in middle age. Fluid intelligence is seen as essentially related to the process of information and involves short-term memory, abstract thinking, creativity, the ability to solve problems, and reaction time. The results of his research on physical activity and cognitive function are showing protective effects of physical activity on cognitive decline and dementia among the elderly. Physical activity has been shown to maintain cerebral blood flow, and possibly increase the aerobic capacity and supply of brain nutrients. Physical activity is also believed to facilitate the metabolism of neurotransmitters.

Giving another assumption about the relationship between physical activity and cognitive function is that the effect of physical activity on cognitive function depends on the intensity and duration (volume) of physical exercise performed [2]. The intensity of physical exercise which is classified as low to moderate tends to support the statement that a physical challenge facilitates cognitive function.

Furthermore, Ratey and Hagerman by carrying out physical activities, there will be a lot of oxygen-filled blood supply that enters the brain [3]. This will stimulate the growth of new cells in the brain so that brain cells will multiply and with the number of new cells, new neurons will be formed which have more synapses which will eventually make the brain able to receive more impulses and be able to store longer and faster to reappear when asked. In addition to many new cell growth, another effect is that it will grow and develop a type of protein in the brain that is called the Brain Derived Neurotropic Factor (BDNF). The function of BDNF itself is to build and maintain cells contained in the brain part of the Hippocampus, which is the part of the brain that is related to the brain's ability to receive and store information obtained, in other words the 
Hippocampus is related to the quality of brain memory work. With the large amount of BDNF in the hippocampus, the memory capacity of the brain will be better and longer lasting.

So it is clear that physical activity can affect memory performance. Conversely, if lack of movement in this case does not do physical activity due to unhealthy lifestyles, it will cause a decrease in one's memory performance. From some of these findings, a problem can be raised that the high demands of work that requires good body condition must be supported by a healthy lifestyle, namely by doing physical activities, one of them is by cycling. This problem was raised because the absence of empirical data regarding research aimed at people already working, which requires the demands of working memory especially in the productive age between the ages of 20 to 35 years.

But in reality now with the rapid technological advancements, physical activity is often overlooked. Everyone prefers to be creative compared to doing sports. They prefer to use a vehicle instead of having to walk (hiking) or use a bicycle as a medium of travel.

Lately, the Bike to Work community has been abbreviated as $\mathrm{B} 2 \mathrm{~W}$, which has increased the popularity of bicycles as a replacement vehicle for motor vehicles to go to work. There are interesting phenomena that can be studied in this bike to work community. For office workers, cycling not only makes life healthier, but is also believed to help to refresh one's memory or memory.

Holmann in his research revealed that young people (students) who exercise cycling are known to have blood flow to the brain increases $30 \%$ [4]. The increasing blood flow in the brain will trigger the brain to release a number of proteins, including a type of protein that grows in the brain that is called the Brain Derived Neurotropic Factor (BDNF) which causes the growth of new nerve cells in the Hippocampus which serves to store memory in time long and minimize the occurrence of concussions. With the growth of BDNF, students who ride bicycles are relatively faster and better at completing their test than students who do not ride bicycles.

The human memory system has two forms, namely short term memory and long term memory. Short-term memory has a role as a place to store memories that are only temporary or in other words, information can be remembered after a few minutes of attention and memorization. While Long-term memory, is a part of the human brain that has the task of storing memories for a long period of time. Long-term memory will save memory in the brain and will make someone remember it for a long time and make the process of motion that automation.

Based on the explanation above, the focus of the research conducted is to describe the effect of cycling activity on the ability of the short term memory for the culprit. This is due to the fact that the first impairment of memory impairment is short-term memory and will result in brain function not being optimal.

\section{METHOD}

The research method used in this study is ex post facto with an intact-group comparison approach. The method used is more focused on comparative research. The purpose of ex post facto research is to look at the consequences of a phenomenon and examine the causal relationship of the data after all the collected events have been completed.

\section{A. Research Design}

This study uses a research design that describes the flow of lines of thought. Research Design Causal-Comparative.

\section{B. Population and Samples}

In this study the authors took the population of 128 active bicycle to work members. While the sample is 30 people, the amount is based on the results of categorization of samples that are in accordance with the characteristics of the study. As for comparison, the authors used a control group (using motorized vehicles) as many as 30 people, and the number was based on the results of categorization which determined the criteria were the same as the samples studied.

\section{Research Instrument}

The instrument used to obtain data on the ability of short term memory is the Letter Test or Number Test. This test tool was adopted from Miller research, the steps for implementing the test are as follows [5]:

- Samples are shown letters or numbers that have been arranged (but do not contain meaning) gradually. Starting from two digit letters up to 16 digit letters for 10 seconds for each stage / level.

- After the letters are displayed for 10 seconds, the sample is then asked to rewrite the letters or numbers This is done in stages until the sample is unable to correctly write the letters or numbers shown earlier.

- The level of ability of the short terms memory sample is determined at the stage / level where the sample is able to correctly mention the entire letter or number shown

\section{RESULTS AND DISCUSSION}

After testing the sample (cycling activity group and control group that does not do cycling / motorized activities), namely short term memory ability test data by using the latter test or number test and getting the results, the next step is to process the data so that the scores obtained have meaning.

Descriptions of data on short term memory capabilities can be seen that the average group that uses bicycles when they go to work short term memory abilities is higher than the average group that uses motorbikes. This can be assumed that groups using bicycles have better short-term memory capabilities compared to motorcycle groups.

The first step taken before testing the hypothesis is to do a normality test, the results are as follows:

The probability value (Sig.) for the cycling sample based on the Kolmogorov Smirnov test is 0.200 greater than 0.05 . 
Likewise, for motorized groups tested using Kolmogorov Smirnov analysis, the probability values (Sig.) 0.142 were greater than 0.05. Referring to the provision that, if the probability value or significance is greater than 0.05 , then the data is normally distributed. Based on the results of the analysis of the data, it can be concluded that the data on the ability of short-term memory for the cycling group and motorized groups are at the Normal distribution level.

The probability value (Sig.) For short term memory based on the average value is 0.187 and greater than 0.05 and based on the median (middle value) the probability (Sig.) Is 0.229 and greater than 0.05 . Referring to the decision criteria, it can be concluded that the short term memory data for cycling groups and motorized groups have the same variance, meaning that the research data is Homogeneous.

Thus, testing for the short term memory data of cycling groups and motorized groups can use parametric statistical testing because the data are normally distributed and homogeneous.

Furthermore, the data obtained was calculated using a different test, namely to determine the effect or difference between the short term memory ability of the cycling group and the control group. Testing is done by comparing the average value $(\mathrm{t})$ between the cycling group and the control group.

The F-count value in the table for Short term memory between the cycling group and the control group is 1.784 with probability (Sig.) 0.187. Because the probability (Sig.) Is $0.187>0.05$ then H0 Accepted. So the two variances have no significant difference. In conclusion, the variance of the ability of the Short term memory between the cycling group and the control group was the same or not significantly different. Thus the average test (t) refers to the values in the row column assuming the same variance.

The value of t-count Short term memory of the cycling group with the control group was 2.144 with probability (Sig.) 0.036 . Because the probability (Sig.) $0.036<0.05$ then $\mathrm{HO}$ is rejected. This means that there are significant differences between the Short term memory cycling group and the control group. Based on the results of the processing, it can be concluded that, cycling activity has a positive influence on the ability of Short term memory.

Based on the results of the processing, it can be concluded that cycling activity has a positive influence on the ability of Short term memory. Thus cycling activities not only provide positive influence on body fitness but also to improve brain work functions, especially those related to the quality of memory possessed.

\section{CONCLUSION}

Based on the results of data processing and analysis that the author has done, then conclusions can be drawn from the results of the study. It is based on the facts and data that the writer has, the conclusion is that cycling activity can affect the ability of Short term memory. This is evidenced by the ability of the Short term memory owned by the cycling group better than the ability of the group's Short term memory using motorbike (control).

\section{REFERENCES}

[1] Manoux, Singh, Archana, "Effects of Physical Activity on Cognitive Functioning in Middle Age: Evidence From the Whitehall II Prospective Cohort Study," American Journal of Public Health, 2005.

[2] Y.V. Auweele, F. Bakker, S. Biddle, M. Durand and R. Seiler, Psychology for Physical Educators. Champaign, Illinois: Human Kinetics, 1999.

[3] J.J. Ratey and E. Hagerman, SPARK : The Revolutionary New Sciene Of Exercise and the Brain. NewYork : Little, Brown and Company, 2008

[4] A. Tieneke, "Meningkatkan kecerdasan Anak dengan Olahraga," [online] Retrieved from: http://www.tieneke.com/ access on 26 September 2008.

[5] G.A. Miller, "The Magical Number Seven," The Psychological review vol. 63, pp. 81-97, 1956 